\title{
El patrimonio es un umbral: presentes sucesiones de presente
}

Aurora Villalobos Gómez | Real Academia de Nobles Artes de Antequera

URL de la contribución <www.iaph.es/revistaph/index.php/revistaph/article/view/3891>

La idea de "patrimonio" surge de un sentimiento de pérdida hace menos de doscientos años $y$, desde entonces, hemos recorrido un camino hacia el "bien cultural" que nos ha llevado a un cambio de paradigma por medio de la desconstrucción del propio concepto, desligándolo de las connotaciones pasivas de pertenencia (lo heredado, objetual) hacia las de apropiación activa (lo generado, subjetual).

La primera mirada fue hacia los monumentos, que previamente a su existencia ya habían sido concebidos como futuros testigos de un eterno pasado memorable. Dado el inherente valor artístico y el valor de antigüedad adquirido suscitaron las primeras teorías de la restauración, que de un primer interés por el objeto aislado ampliaron su ámbito de actuación al contexto.

Siguen siendo protagonistas de la escena patrimonial por su excepcionalidad, ya que comprenden las grandes creaciones de la historia de la humanidad, teniendo su reflejo más evidente en la lista del patrimonio mundial de UNESCO. Sin embargo esto no garantiza su tutela (centrada en la protección y conservación), ya que son varios los nuevos fenómenos que, por exceso, los desvirtúan de su autenticidad como la museificación de los centros históricos por el turismo masivo o una sacralización que induce a la réplica de bienes y espacios patrimoniales que modifican la experiencia cultural.

Afortunadamente también se dan nuevas oportunidades de interacción, como con el arte contemporáneo, probablemente porque compartan la misma finalidad estética y la capacidad de expresar la realidad de una manera creativa. Pensemos en la función del cine como generador de nuevos imaginarios sobre nuestros bienes culturales, el fenómeno de las exposiciones temporales en contextos patrimoniales o el propio uso como museos de arte contemporáneo de contenedores históricos.
Conforme se han ido incorporando nuevos criterios de valoración de carácter científico se ha abierto la posibilidad de reconocer otros elementos patrimoniales por su singularidad como documento, susceptible de ser leído desde sus propias claves disciplinares. Esta nueva mirada ha ofrecido oportunidades a patrimonios emergentes como el industrial, subacuático, etnológico, y el contemporáneo, donde la investigación se convierte en la acción patrimonial crucial para la fundamentación del bien.

La comprensión de la vida del bien desde la lógica histórica conlleva el reconocimiento de todas las épocas como presentes pretéritos; sin embargo se sigue produciendo una distancia mental hacia el patrimonio contemporáneo por la que es más fácil entender un edificio de nueva planta (como monumento) que una intervención contemporánea en un contexto patrimonial (como documento). Pensamos que esto sucede porque la conservación se malinterpreta en oposición al uso, cuando lo cierto es que los productos culturales de la modernidad no sólo pueden convertirse en bienes protegibles sino que además nos pueden ayudar a explicitar o trascender los valores propios de las preexistencias.

Esta incomprensión social se pone de manifiesto con la destrucción impune de singulares edificios modernos por sus propios propietarios y la oposición casi sistemática a cualquier intervención sobre el patrimonio consolidado. Tenemos por delante una importante tarea de difusión para que se resuelva el debate (superado por los especialistas a finales de los años cincuenta) sobre la inserción de la arquitectura de nuestro tiempo. Porque de otro modo se insiste en poner un límite artificial a lo contemporáneo en vez de asumir una lectura continua, incorporando el bien a la época actual a partir de una valoración de tipo arquitectónico que concilie las necesidades del bien y de los usuarios. 


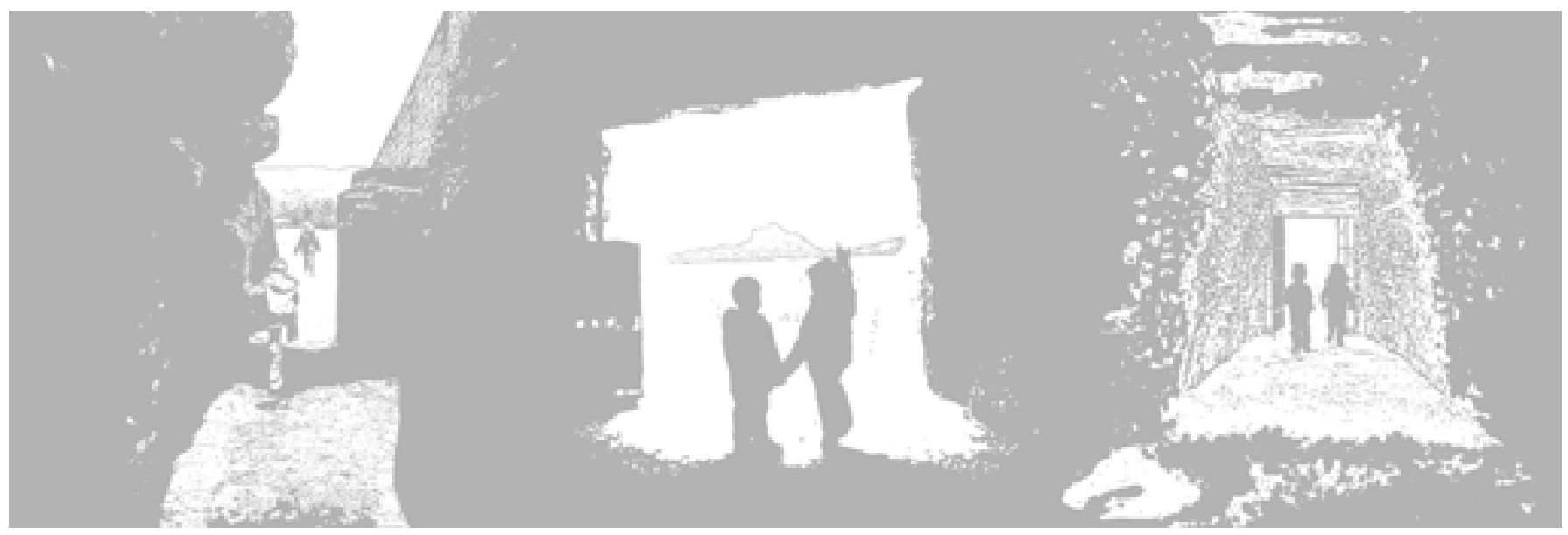

Umbrales | imagen Aurora Villalobos Gómez, 2017

Una vez que el patrimonio se convierte en un proceso relacionado con la elección de valores más que en una propiedad intrínseca al bien, se pasa a entender, más que como un conjunto de bienes catalogados, como una construcción social por la que las personas se identifican con determinados bienes del pasado que quieren disfrutar en el presente y conservar para el futuro, estén o no declarados oficialmente.

Esta nueva mirada desde la identidad ubica a la persona junto al objeto en el centro de la acción patrimonial, recuperando el vínculo con lo local y explicitándose el patrimonio inmaterial. Son los rituales festivos, oficios y saberes, modos de expresión y alimentación que, a su vez, llevan asociada la existencia de unos elementos tangibles (de carácter mueble e inmueble, permanente o efímero) para el desarrollo de su actividad. Se trata, por lo tanto, de un patrimonio vivo que requiere de nuevas estrategias de tutela ya que su prioridad no es la materialidad (el patrimonio) sino la autenticidad de la acción en el presente (lo patrimonial); llegando a suplantar el sujeto al objeto en lo que algunos han denominado la "patrimonialización del hombre". El reto actual consiste en revisar para éstos los criterios de intervención consensuados para el patrimonio material ya que paradójicamente muchas de sus manifestaciones visibles recurren en nombre de la identidad al mecanismo de reconstrucción desaconsejado por ley.
Por último, el patrimonio se ha posicionado como un recurso sostenible en el territorio, que cualifica la vida de las personas para resolver cuestiones actuales, con un enorme potencial económico al implementarse las políticas culturales con otras estrategias de desarrollo. Esto ha devenido en que "conocer para intervenir" el patrimonio no significa sólo diagnosticarlo para reconocer pautas de actuación sino que, en un sentido más amplio, es necesario que todo el conocimiento generado redunde en su valoración y disfrute. Esta mirada se traduce en nuevos modelos de museo-franquicia como estrategia de marketing urbano; el auge del turismo rural por efecto de la glocalización; la tendencia a reconstrucciones didácticas desde la arqueología experimental; o nuevos intereses de la arqueología como instrumento crítico para interpelar a la sociedad.

Estas consideraciones tienen consecuencias en los procesos de patrimonialización porque implican que ya no solo la administración es la que designa los bienes con voluntad de ser recordados (monumento/valor estético), ni los especialistas los que identifican los bienes de interés para la cultura (documento/valor científico) sino que la sociedad irrumpe como un nuevo agente, rastreando en él su memoria colectiva (identidad/valor simbólico) y asociándolo a su tiempo libre de ocio (recurso/valor económico). Sin embargo, para que estos nuevos fenómenos de participación no sean arbitrarios en la toma 
a debate Visiones patrimoniales para definir el objeto del siglo

| coordinan José Ramón Moreno Pérez, Marta García de Casasola Gómez

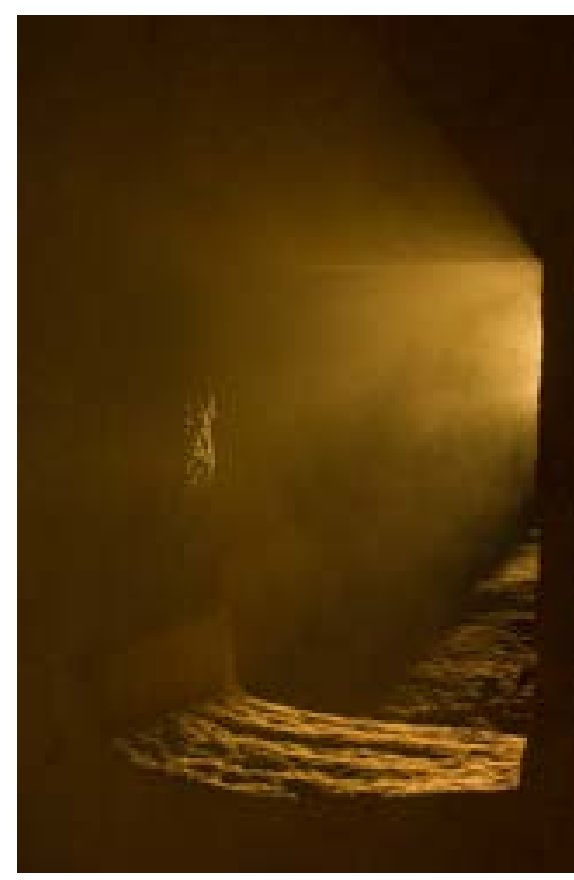

Amanecer del equinoccio de otoño en Viera

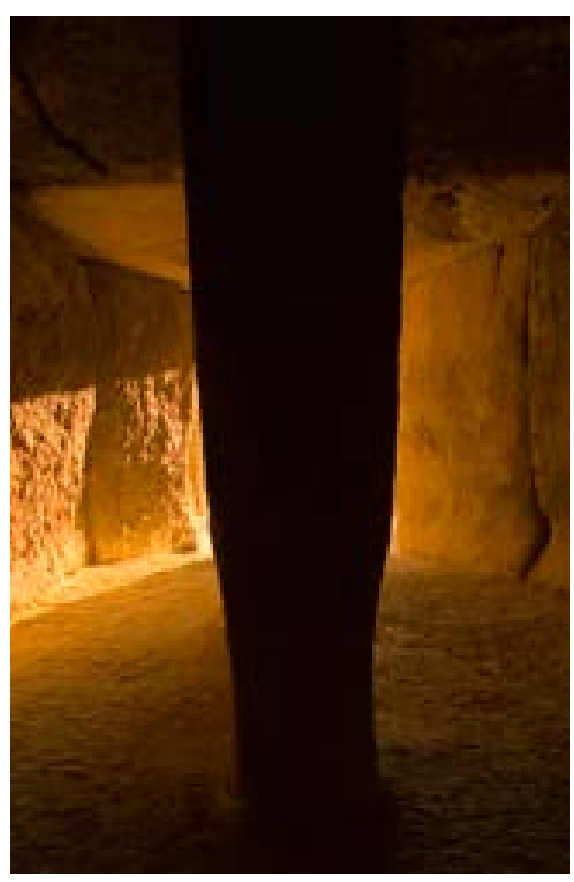

En el eje de Menga

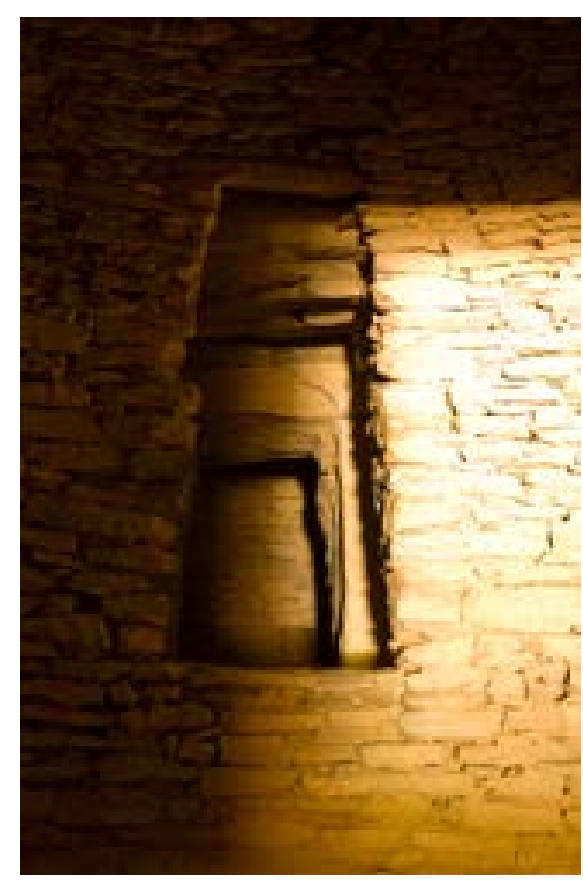

Proyección solar durante el solsticio de invierno en el Romeral | fotos Conjunto Arqueológico Dólmenes de Antequera (Javier Pérez González) de decisiones sobre qué bienes deben ser protegidos y cómo, la valoración cultural debe descansar sobre una investigación rigurosa que comprenda todas las disciplinas interpeladas.

El patrimonio se nos presenta en el siglo XXI como un umbral que puede atravesarse en ambas direcciones (contemplando el pasado o proyectándonos al futuro), donde inevitablemente actuamos desde el presente (un límite difuso, más o menos construido, que nunca permanece igual); y que invita siempre a un nuevo itinerario desde la experiencia de lo conocido (no hay nuevos objetos sino nuevas miradas). En definitiva, el patrimonio hemos pasado a entenderlo como presentes sucesiones de presente que nos remiten a un sucesivo encuentro entre pasado y futuro, donde confluyen las miradas interesadas desde la contemporaneidad como monumento, documento, identidad y recurso. En la medida en que las integremos será más eficaz la tutela del patrimonio cultural.

\section{BIBLIOGRAFÍA}

- AGUDO TORRICO, J. (2012) El tiempo de las identidades híbridas. En GUERRA DE HOYOS, C.; PÉREZ HUMANES, M.; TAPIA MARTÍN, C. (coord.) Temporalidades contemporáneas, incluido el pasado en el presente. Sevilla: Instituto Andaluz del Patrimonio Histórico, 2012, pp.40-53 (PH Cuadernos; 29)

- CASTILLO RUIZ, J. (2007) El futuro del patrimonio histórico: la patrimonialización del hombre. E-rph. Revista electrónica de patrimonio histórico, n. ${ }^{\circ}$ 1, 2007, pp. 1-35

- FERNÁNDEZ-BACA CASARES, R. (1996) La ciudad patrimonial. PH Boletín del Instituto Andaluz del Patrimonio Histórico, n. ${ }^{\circ}$ 14, 1996, pp. 88-95

- FERNÁNDEZ SALINAS, V. (dir.) (1996) Bases para una Carta sobre Patrimonio y Desarrollo en Andalucía. Sevilla: Instituto Andaluz del Patrimonio Histórico, 1996

- MORENTE DEL MONTE, M. (2007) Museo y patrimonio. Del objeto a la planificación estratégica. Museos, n. 3, 2007, pp. 16-29 